\title{
Strategic planning in media organizations of Iran
}

\author{
Ali Akbar Farhangi ${ }^{a^{*}}$, Mohammad Soltani Far ${ }^{b}$, Ali Asghar Mahaki ${ }^{\mathrm{c}}$ and Abolfazl Danaei ${ }^{\mathrm{d}}$
}

${ }^{a}$ Full Prof. \& The Head of Media Management Department, Science and Research Branch, Islamic Azad university, Tehran, Iran ${ }^{b}$ Assistant Prof. \& The Head of Communication Department, Science and Research Branch, Islamic Azad university, Tehran, Iran ${ }^{c}$ General Manager of Social and Cultural Studies in Tehran Municipality, Iran

${ }^{d}$ Ph.D. Student of Media Management Department, Science and Research Branch, Islamic Azad university, Tehran, Iran

A R T I L E I N F O A B T R A T

Article history:

Received June 2, 2011

Received in Revised form

October, 19, 2011

Accepted 28 December 2011

Available online

7 January 2012

Keywords:

Strategic management

Balanced score card

Media organizations

Hamshahri newspaper

Triangular Fuzzy DEMATEL
Organizations with activities of all kinds are influenced by environmental conditions, and external environment is in fact the beginning point of the strategy. Strategic management is an approach resulting from fast changing age and can consider it as a view and a technique for flexible planning to fast changes, and balanced score card is regarded as one of the strong instruments in this zone. Balanced score card can truly plays an important role in all stages of strategic management and the efficiency of this model is considerably regarded in management performance evaluation in different organizations. However, strong instrument such as balance score card is hardly used because of long term dominance of political approaches in the management of Iran media organizations. This paper conceptualizes administrational trend of strategic planning by implementing balanced score card and we draw strategy map and determine performance indexes in a written media organization (Hamshahri Newspaper).

\section{Introduction}

Media dominance on today's human life in one respect and fast, wide and extended changes in all dimensions of human life in another respect has led to the revelation of a perfectly different strategic environment. These developing and fast economic, social and cultural changes have also influenced on all dimensions of the organizations. Furthermore, it has produced new requirements and expectations for the organizations. These requirements and expectations have increasingly converted the role and duty of managers and leaders. Along with reaction to these conversions and new produced space, application of new management methods is inevitable. One of the applied methods for managing the organizations in complicated conditions with high change rate is the strategic management, which are a view and a technique for flexible planning. One of the powerful instruments in the strategic management is balance score card, which can be used in all stages of the strategic management and make the management performance evaluation possible.

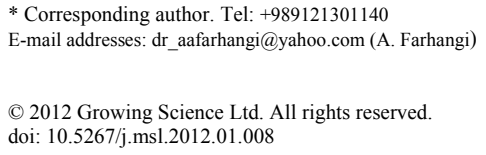


Survival of economic and noneconomic enterprises is in performance improvement for maintaining the increase in competitive power and finally attainment of more benefits and that media organizations are not excluded from this regulation. This significance is probed by goal setting and appropriate planning and accurate performance evaluation for being aware the success extent in achieving the predetermined objectives. Achievement of great success is in the development of management and performance evaluation system. Therefore, the use of balanced evaluation system as an efficient system can cover the weaknesses and shortcomings of traditional performance evaluation by reliance on new performance index and then direct the organization towards the achievement of greater success. In addition to financial indexes, which were emphasized in traditional system, non financial indexes in which many managers were confronted with failure, were also considered in this comprehensive evaluation system and has been kept far from mere attention to financial indexes which is only in relation to post performance of the organization.

The proposed model of this paper conceptualizes the administrational trend of strategic management in balanced score card framework up to strategy planning and performance indexes in a written media organization of Iran (Hamshahri Newspaper) with regarding the available problems for drawing the strategy map in this paper.

\section{Review of strategic management concepts}

The word strategy, which is derived from Greek word was used about $400 \mathrm{bc}$ and was dedicated to the art and science of conducting military forces. Anyway, in the late $18^{\text {th }}$ century, strategy meant the composition science and performance, which superior commanders applied (Brews, 2007). In this way, strategy definition expanded to the expansion of strategic management field has been a popular method in the last three decades (Gordon, 2004). Strategic management is the art and science of designation, implementation, and investigation of multi task-based decisions, which enable the organization in achievement of its long-term objectives (David, 1997; Hunger \& Wheelen, 2000). The aim of strategy designation is to define mission and vision, to determine threats as well as strength and weakness, create organizational objectives and to consider strategic planning components (David 1997).

2.1 Vision and mission statement: mission and vision setting stage is one of the most important stages of strategic planning which is conceived less than other stages (Ralph, 2007). In the trend of strategic planning of each organization, mission and vision are to an extent important for to the organization as the main task in strategic management from the view of mission and vision (Drucker, 1974).

Mission statement is a document which distinct the organization from other similar organizations (David, 1997), and vision expresses clearly the future ideal situation of an organization. This definition is too effective in activities of organization that (Pearce \& David, 1989) according to the reported results, the vision of the organizations having strong performance is more eminent that the organizations having weak performance. The aim of vision definition is to create a shared view of the future of the organization for every staffs especially for leaders of the organization (Ralph, 2007).

2.2 Strategic Themes: the most prominent driver of organizational achievement for the organizations has been the performance of their processes in 2000 and this trend will continue. Raval and Ficharia (2007) considered the control of the related processes on the most appropriate way of management. The related processes can include hundreds of sub-processes, which produce value in various ways. Managers who apply strategy art should define important processes, which are significant for the creation and representation of distinct value to customers. Kaplan and Norton (2004) called these significant processes, the Strategic Themes.

2.3 General Objectives of the organization: the objectives of the organization can be macro, strategic, trivial, executive or operational. General objectives provide total conduction of the organization 
(Gordon, 2004). General objectives are set in the organizational macro level and trivial objectives are defined in lower level. The definition of Okumus is enough for expressing the importance of objectives level, the definition which considers the strategic management process as the formulation of organizational objectives (Okumus, 2002).

2.4 Environmental analysis and SWOT matrix: SWOT analysis was designed and represented by Stanford research institute in 1960 and was mainly applied as an analytical framework for strategy appointment of the organizations since early 1975 and yet has been applied by today research (Hassanzadeh Amin \& et. al., 2011; Celik \& et. al., 2009; Yuksel \& Dagdeviren, 2007; Gao \& Peng, 2011; Lee \& Walsh, 2011; Manteghi \& Zohrabi, 2011; Boytsov \& Van de Werf, 2011; Biancamaria \& et. al., 2011; Wang \& Hong, 2011; Liu \& et. al., 2011; Mihaela \& et. al., 2011; Misra \& Murthy, 2011; Hauttekeete \& et. al., 2011; Siddique-E-Akbor \& et. al., 2011; Rizzi \& et. al., 2011; RoedLarsen \& Stoop, 2011; Chen, 2011; Hall \& et. al., 2010; Grosseck \& Holotescu, 2011; Sanagustin Fons \& et. al., 2011; Markovska \& et. al., 2009; Lee \& Lin, 2008; Isgören \& Ayla, 2009). SWOT analyzes the strengths and weaknesses, threats and opportunities for the expected strategy conduction (Rauch, 2007). This matrix is a useful instrument for strategic planning in the environmental management and is considered as a fundamental basis for determining conditions and planning the future methods, which is essential for strategic attitude (Nikolaou \& Evangelinos, 2010).

2.5 Strategies: Webster-Miriam dictionary describes the strategy as "an accurate map, plan or method especially for achieving an objective but concise and useful definition of this word is generally difficult, and persistence on each special meaning for it will be useless such as many other words which are long used in various fields" (Olve \& Sjöstrand, 2002).

\section{Balanced score card}

Balance score card is one of the tools for performance evaluation, which can clarify intangible assets of the organization and indicate the mission (Tohidi \& et al., 2010) and vision of the organization in the form of cause-effect relations in four aspects of financial, customer, internal processes, growth and learning (Achterbergh \& et al., 2003). Balanced score card management system is a structure of performance evaluation criterion, which includes past, present and future performance indexes and sets the non-financial criteria in addition to financial ones. Meanwhile, from what is occurred inside and outside of organization, multilateral visions and insights will be presented to managers of the organization (Akkermans \& Von Oorschot, 2000; Linard \& Yoon, 2000). Kaplan and Norton believe that successful strategy implementation of the organization depends on the fact that organizational individuals perceive and realize the strategies. It should be mentioned that, the mentioned affair is required to produce complicated processes, which cause the organizational intangible assets and capitals are converted into tangible and sensible outputs. In this respect, balanced score card innovators, introduced the strategy map as an instrument which can represent the link between strategy structures of organization by determining and deriving the key objectives of organization and conceptualization of cause-effect relations between them (Kaplan \& Norton, 2004). Unfortunately, many organizations and enterprises face a lot of problems in their score card path, as they make serious mistakes in drawing their strategy map (Creelman \& Makhijani, 2008).

\section{The strategic model of media organizations}

Organizations with activities of all kinds are influenced by environmental conditions and external environment is in fact the beginning point of strategy, they are not only influenced by environment but may also influence on their own environment. There is undoubtedly impressibility from environment for all the organizations. However, media organizations have increasingly wider and more extended influence on cultural, economic and political conditions even on customer perception 
and as a result on attitudes of the society and government towards different problems. This feature, that is, the extent of media influence on environment, makes media organizations different from other organizations. There are evidences indicating that media have especial influence on addressee's perception (Van Dijk, 1998). There are generally many studies, which indicate that media extremely influence resource credibility and individual mentality (Parenti, 1993; Bell, 1991; Soley, 1992; Valentino, 1999; Jamieson, 2003; Gerstl-Pepin, 2002; Dreier, 2005; Cohen, 1963).

In addition, there are empirical evidences of performed researches by different researchers in late $90 \mathrm{~s}$ and early 2000 that news group Medias extremely influence on public perceptions about their discussions (Alderman, 1994; Druckman, 2005; Gilens, 1999; Gilliam et al., 1996; Iyengar \& kinder, 1987; Koch, 1994; Page \& et al., 1987). Therefore, event clarification, emission and influences, even scientific events, depend on Medias. So Medias in different cultural, social, economic and political fields are considered as the constituent of legitimacy base. Like other organizations, managers of media organizations should identify their environment by appropriate perception of their influencing power on environment and move along its dominant changes. They must overcome on organizational constraints (weaknesses) by the use of resources (strengths). With respect to the projected issues, the most important features of strategic planning can be as following:

4.1. Utilization of inter-organizational resources: one of the objectives of strategic management is to utilize inter-organizational resources. Attention to organizational quadruplet elements including human resources, capital and skeletal possibilities and instruments, relations and structures as well as organizational culture are of significance for utilization of these resources. Each of these elements has divisibility to many sectors and credible and accurate information must be collected about them in the strategic management.

4.2. Environment has an irrefutable influence on each strategic approach: Success of the strategic management depends on correct, accurate and multilateral investigation of organizational environment. Environment is divided to three major groups:

a) Industry environment (activity environment): the main players in activity or industry environment in Medias are customers or addressees, competitors and suppliers, society, government and organization owners, stakeholders and beneficiaries.

b) General environment (Close environment): the role players in this environment are ecology conditions, economic, political, social, legal and juridical conditions, cultural conditions, and governing conditions on bureaucracy and technology changes or dominant technology.

c) International environment (remote environment): influencers in this part include four major parts which are: globalization trend, technological and scientific improvements, fall of communist and dictatorial regime and ideologist conflicts and biological crisis.

Above features can indicate the parts of a comprehensive strategic model in Media organizations with effective dimensions on media organizational objectives. It should be noted that each environmental factor can be divided into smaller parts and can also be investigated. Note that if the strategy is implemented, all the projected parts must be arranged in one line. The environmental survey part (internal and external analysis) of diagram indicates an application of above features in the conceptual model of present paper.

\section{Research methodology}

The framework of diagram1 can be considered for Media organizational strategic planning such as Hamshahri newspaper which we will pay to analysis of its part in the following. 


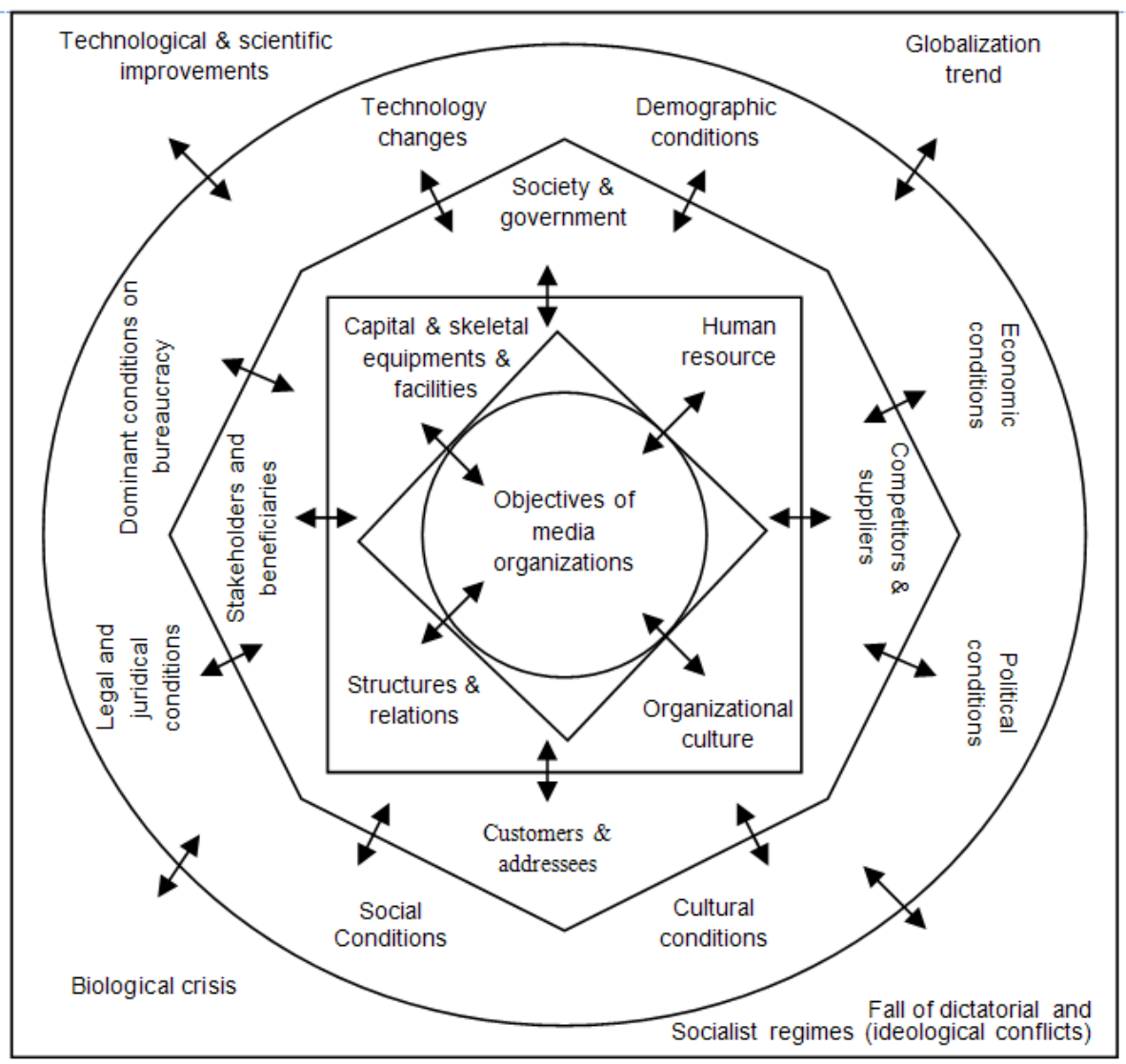

Fig. 1. Strategic comprehensive model in media organizations

5.1. Constitution and state vision: All the organizations in one country should be precursor of rules and macro policies of a unit such as constitution and state vision. Otherwise, they can waste significant amount of valuable time of the organization, make organizational objectives unstable, deviate human forces and finally lead to the loss of a large number of employees. Sometimes, decisions made for strategy adoption in the organizations are based on political biases and personal tastes, which is an inelegant affair. Imitation of a unified vision by the organizations can prevent of this occurrence.

5.2. Mission and vision appointment: Mission and vision statements determine the main objectives and direction of the organization. The organization should describe the reason and the way of its presence in business environment in this step.

5.2.1 Internal and external analysis: As it is obvious in Fig. 2, effective external environment on media organizations can be divided into three groups of industry environment (activity environment), general environment (close environment) and international environment (remote environment) and that each of triple environments produce weaknesses and strengths for the organization. In addition, factors such as human resources, capital and skeletal facilities and instruments, structures and relations and organizational culture can be investigated based on their weaknesses and strengths. This stage can be performed by SWOT matrix. SOWT analysis was designed and presented by Stanford research institution in 1960s and was mainly applied as an analytical framework for organization strategy preparation since early 1975 and is still applicable for today researches after its long time presentation. 


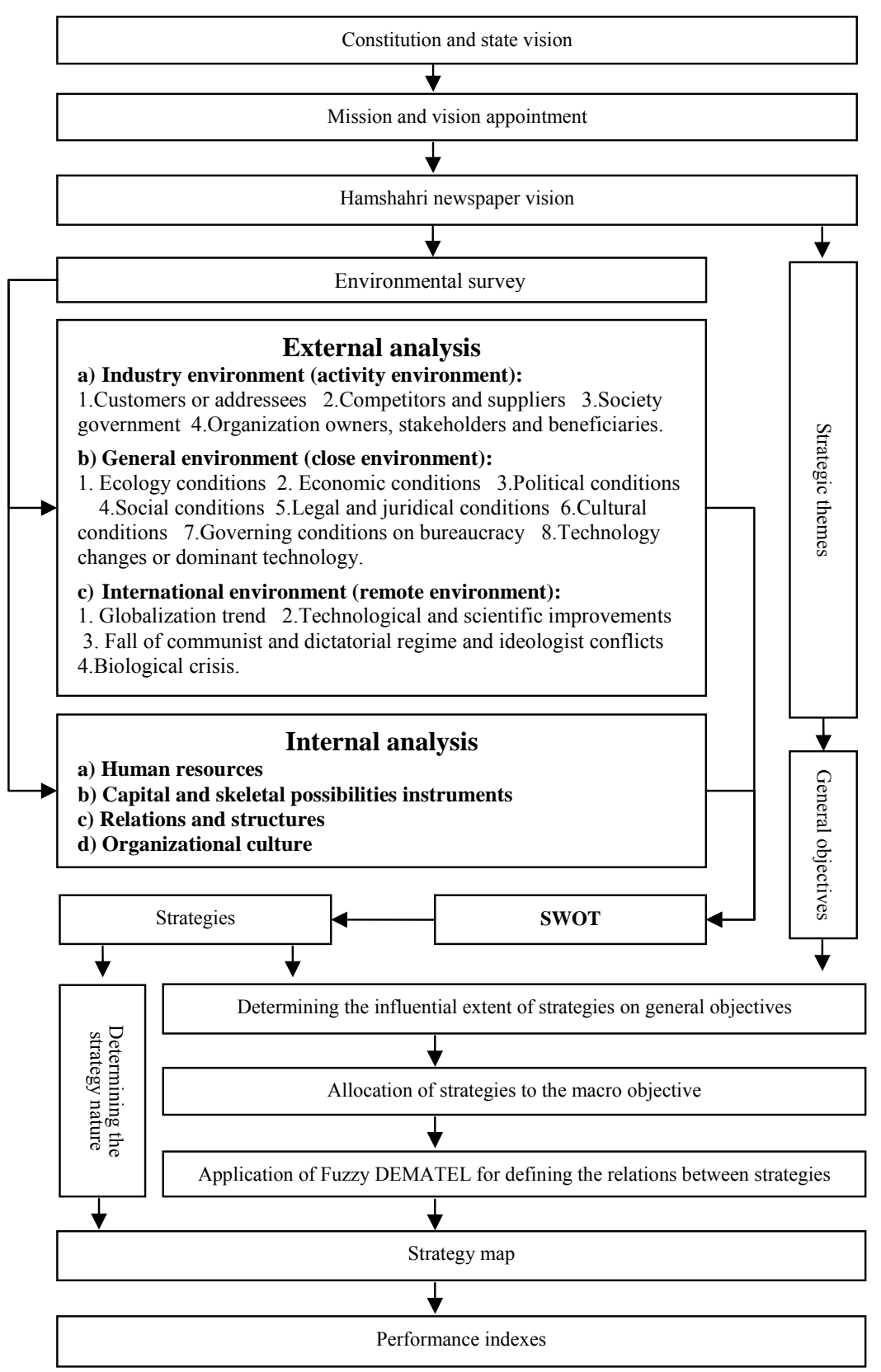

Fig. 2. The strategic planning framework in Hamshahri newspaper

5.3. Strategies: The strategies are instruments in which organizations can achieve their long-term objectives. The strategy of organization can be as the form of developing the activities, purchase of other company's production and product supply, market penetration, cost reduction, sale of a number of assets, authority turn over and formation of private involvements. These objectives are achieved by analyzing weaknesses and strengths and opportunities \& threats, which are performed by SWOT matrix.

5.4. Strategic Themes: The strategic implications define important processes, which are valuable in organizational vision for creation and representation of diverse value to customers. These processes should be followed in the total life of the organization to vision achievement (Kaplan \& Norton, 2004). The important processes, which are significant for producing and presenting distinct value to customers should be defined in proportion to organizational mission and vision in this stage.

5.5. General Objectives determination: This stage forces the analysts and managers of the organization to investigate each of strategic implication (as the continuous processes in the 
organization) for vision achievement. Successful implementation of this stage can contribute to the better recognition of implications for their operationalization by exploration and definition of macro objectives, since macro objectives can draw images more obvious than the processes of the organization. Therefore, one or more macro objectives can be defined for each strategic implication.

5.6. Determining the influential extent of strategies on General Objectives: Accomplishment of Table 1 is done by the contribution of expert group in this step (Weighted average is applied for the combination of expert group's opinions in this survey).

\section{Table 1}

The matrix of strategy influential extent on General Objectives

\begin{tabular}{llll}
\hline & General objectives & & \\
Strategic objectives & $O_{1}$ & $\ldots$ & $O_{n}$ \\
\hline$S_{1}$ & $V_{11}$ & $\ldots$ & $V_{1 n}$ \\
$\vdots$ & $\vdots$ & $\ddots$ & $\vdots$ \\
$S_{m}$ & $V_{m 1}$ & $\ldots$ & $V_{m n}$ \\
\hline
\end{tabular}

Table 2 summarizes the linguistic terms used for the proposed model of this paper.

Table 2

Nominal variables

\begin{tabular}{llll}
\hline Linguistic variables & Quantitative value & Linguistic variables & Quantitative value \\
\hline Very low & 1 & Medium - High & 6 \\
Very low - Low & 2 & High & 7 \\
Low & 3 & High - Very High & 8 \\
Low- Medium & 4 & Very High & 9 \\
Medium & 5 & & \\
\hline
\end{tabular}

5.7. Allocation of strategies to the macro objective: influence adjustment is done by omitting weak relations in this step. In this paper, for example, this allocation is done by considering the most efficient ones and discarding the others.

5.8. Application of Fuzzy DEMATEL for defining the relations between strategies: DEMATEL was first applied by American scientists in 1972-1976 for solving the complicated problems in human science and programs. DEMATEL was established based on Graph theory, which is capable of analyzing and solving the problems by diagram drawing. This modeled structural approach based on direct graph is in conformity with cause-effect diagram, which determines the relations among factors and the influential degree of each one. All factors of system are divided into impressible and influencing groups and help researchers better understand the structural relationship of system parts and to find solutions for solving the problems of complicated systems (Wu \& Lee, 2007; Gabus \& Fontela, 1973; Wang \& Chuu, 2004; Herrera \& \& et. al., 2000).

With respect to the fact that we require expert's opinions for the use of DEMATEL technique may be vague, we use fuzzy numbers for better handling the numbers. Lin and $\mathrm{Wu}$ (Lin \& $\mathrm{Wu}, 2008)$ presented a model which benefits of DEMATEL technique in fuzzy environment and the following summarize it,

Step1: determine decision objectives and form a committee for opinion collecting in problem solving, Step2: determine evaluation measures based on fuzzy nominal scale,

We use the fuzzy DEMATEL model proposed by Li (1999) for the study of this paper. Different "influencing" degrees are expressed by five words of "very high, high, low, very low, no influence" and their opposite positive triangular Fuzzy numbers are indicated in Table 3. 
Table 3

Fuzzy nominal scale

\begin{tabular}{|c|c|c|c|c|c|c|}
\hline Expression & $\begin{array}{l}\text { Very } \\
\text { influence(VH) }\end{array}$ & High influence(H) & Low influence(L) & $\begin{array}{l}\text { Very } \\
\text { influence(VL) }\end{array}$ & low & No influence(NO) \\
\hline Value & $(0.75,1,1)$ & $(0.5,0.75,1)$ & $(0.25,0.5,0.75)$ & $(0.0,0.25,0.5)$ & & $(0.0,0.0,0.25)$ \\
\hline
\end{tabular}

Step3: collect decision maker's evaluations: One decision making group including $\mathrm{P}$ experts were asked for determining the relations among measures $C=\left\{C_{i} \mid i=1,2, \ldots, n\right\}$ to obtain a set of pair comparison based on nominal expressions. Therefore, P Fuzzy matrix $\tilde{Z}^{\langle 1\rangle}, \tilde{Z}^{\langle 2\rangle}, \ldots, \tilde{Z}^{\langle P\rangle}$ are provided by the use of expert's opinions.

$$
\tilde{Z}^{\langle k\rangle}=\left[\begin{array}{cccc}
0 & \tilde{Z}_{12}^{\langle k\rangle} & \cdots & \tilde{Z}_{1 n}^{\langle k\rangle} \\
\tilde{Z}_{21}^{\langle k\rangle} & 0 & \cdots & \tilde{Z}_{2 n}^{\langle k\rangle} \\
\vdots & \vdots & \cdots & \vdots \\
\tilde{Z}_{n 1}^{\langle k\rangle} & \tilde{Z}_{n 2}^{\langle k\rangle} & \cdots & 0
\end{array}\right] \quad k=1,2, \ldots, p
$$

In which fuzzy matrix $\tilde{Z}_{i j}^{\langle k\rangle}=\left(\lambda_{i j}^{\langle k\rangle}, m_{i j}^{\langle k\rangle}, u_{i j}^{\langle k\rangle}\right)$ is called primary direct relation fuzzy matrix of the number K expert.

Step4: obtain the normal matrix of Fuzzy direct relation,

Let $\tilde{a}_{i}^{\langle k\rangle}$ be triangular Fuzzy numbers,

$$
\begin{aligned}
& \tilde{a}_{i}^{\langle k\rangle}=\sum_{j=1}^{n} \tilde{Z}_{i j}^{\langle k\rangle}=\left(\sum_{j=1}^{n} \lambda_{i j}^{\langle k\rangle}, \sum_{j=1}^{n} m_{i j}^{\langle k\rangle}, \sum_{j=1}^{n} u_{i j}^{\langle k\rangle}\right) \\
& r^{\langle k\rangle}=\max _{1 \leq i \leq n}\left(\sum_{j=1}^{n} u_{i j}^{\langle k\rangle}\right)
\end{aligned}
$$

Then, conversion of linear scale is used as the form of normalization formula for converting the measure scale to comparable scales. Normalization matrix of $\mathrm{k}^{\text {th }}$ expert Fuzzy direct relation, which is, $\tilde{X}^{\langle k\rangle}$ is indicated as following,

in which

$$
\tilde{X}^{\langle k\rangle}=\left[\begin{array}{cccc}
\tilde{X}_{11}^{\langle k\rangle} & \tilde{X}_{12}^{\langle k\rangle} & \cdots & \tilde{X}_{1 n}^{\langle k\rangle} \\
\tilde{X}_{21}^{\langle k\rangle} & \tilde{X}_{22}^{\langle k\rangle} & \cdots & \tilde{X}_{2 n}^{\langle k\rangle} \\
\vdots & \vdots & \cdots & \vdots \\
\tilde{X}_{n 1}^{\langle k\rangle} & \tilde{X}_{n 2}^{\langle k\rangle} & \cdots & \tilde{X}_{n n}^{\langle k\rangle}
\end{array}\right] \quad k=1,2, \ldots, p
$$

$$
\tilde{X}_{i j}^{\langle k\rangle}=\frac{\tilde{Z}_{i j}^{\langle k\rangle}}{r^{\langle k\rangle}}=\left(\frac{\lambda_{i j}^{\langle k\rangle}}{r^{\langle k\rangle}}, \frac{m_{i j}^{\langle k\rangle}}{r^{\langle k\rangle}}, \frac{u_{i j}^{\langle k\rangle}}{r^{\langle k\rangle}}\right) .
$$

We assume $\sum_{j=1}^{n} u_{i j}^{\langle k\rangle}<r^{\langle k\rangle}$.

In practice, this assumption is truly satisfied. Then, algebraic phrases of multiplying a constant in one fuzzy number and plural of two fuzzy numbers are used for calculating the average matrix $\tilde{X}$ originated from $\tilde{X}^{\langle 1\rangle}, \tilde{X}^{\langle 2\rangle}, \ldots, \tilde{X}^{\langle P\rangle}$ 


$$
\tilde{X}=\frac{\left(\tilde{X}^{\langle 1\rangle} \oplus \tilde{X}^{\langle 2\rangle} \oplus \ldots \oplus \tilde{X}^{\langle p\rangle}\right)}{p} ; \tilde{X}=\left[\begin{array}{cccc}
\tilde{X}_{11} & \tilde{X}_{12} & \cdots & \tilde{X}_{1 n} \\
\tilde{X}_{21} & \tilde{X}_{22} & \cdots & \tilde{X}_{2 n} \\
\vdots & \vdots & \cdots & \vdots \\
\tilde{X}_{n 1} & \tilde{X}_{n 2} & \cdots & \tilde{X}_{n n}
\end{array}\right]
$$

where $\quad \tilde{X}_{i j}=\frac{\sum_{k=1}^{p} \tilde{X}_{i j}^{\langle k\rangle}}{p}$.

Fuzzy matrix $\tilde{X}$ is called normal matrix of fuzzy direct relation. Here, we apply the arithmetic average for integrating the total data of experts after calculating the normal matrix of Fuzzy direct relation $\tilde{X}^{\langle k\rangle}$. This method is better than the integrating method of total expert data after calculating the matrix of primary Fuzzy direct relation $\tilde{Z}^{\langle k\rangle}$.

Step5: structural model analysis and implementation

We must first ensure the convergence of $\operatorname{Lim}_{w \rightarrow \infty} \tilde{X}^{w}=0$ for calculating the matrix of total Fuzzy relation. In calculating $\tilde{X^{w}}$ we apply the access relation of $\tilde{n}_{1} \otimes \tilde{n}_{2} \cong\left(\lambda_{1} \times \lambda_{2}, m_{1} \times m_{2}, u_{1} \times u_{2}\right)$ for multiple of two triangular Fuzzy numbers, so, $\tilde{X}^{w}$ elements are also triangular fuzzy numbers.

Let $\tilde{X}_{i j}=\left(\lambda_{i j}, m_{i j}, u_{i j}\right)$ and consider 3 following certain matrixes which its elements are derived from $\tilde{X}$ :

$X_{u}=\left[\begin{array}{cccc}0 & u_{12} & \cdots & u_{1 n} \\ u_{21} & 0 & \cdots & u_{2 n} \\ \vdots & \vdots & \cdots & \vdots \\ u_{n 1} & u_{n 2} & \cdots & 0\end{array}\right] \quad X_{m}=\left[\begin{array}{cccc}0 & m_{12} & \cdots & m_{1 n} \\ u_{21} & 0 & \cdots & m_{2 n} \\ \vdots & \vdots & \cdots & \vdots \\ m_{n 1} & m_{n 2} & \cdots & 0\end{array}\right] \quad X_{\lambda}=\left[\begin{array}{cccc}0 & \lambda_{12} & \cdots & \lambda_{1 n} \\ \lambda_{21} & 0 & \cdots & \lambda_{2 n} \\ \vdots & \vdots & \cdots & \vdots \\ \lambda_{n 1} & \lambda_{n 2} & \cdots & 0\end{array}\right]$

According to certain state, we define the matrix of Fuzzy total relation as follow:

$$
\tilde{T}=\operatorname{Lim}_{w \rightarrow \infty}\left(\tilde{X}+\tilde{X}^{2}+\ldots+\tilde{X}^{w}\right)=X \times(I-X)^{-1}
$$

Theorem: Let $\tilde{T}=\left[\begin{array}{cccc}\tilde{t}_{11} & \tilde{t}_{12} & \cdots & \tilde{t}_{1 n} \\ \tilde{t_{21}} & \tilde{t}_{22} & \cdots & \tilde{t}_{2 n} \\ \vdots & \vdots & \cdots & \vdots \\ \tilde{t}_{n 1} & \tilde{t}_{n 2} & \cdots & \tilde{t}_{n n}\end{array}\right]$ where $\tilde{t_{i j}}=\left(\lambda_{i j}^{\prime \prime}, m_{i j}^{\prime \prime}, u_{i j}^{\prime \prime}\right)$, then Matrix $\left[\lambda_{i j}^{\prime \prime}\right]=X_{\lambda} \times\left(I-X_{\lambda}\right)^{-1}$ and Matrix $\left[m_{i j}^{\prime \prime}\right]=X_{m} \times\left(I-X_{m}\right)^{-1}$ and Matrix $\left[u_{i j}^{\prime \prime}\right]=X_{u} \times\left(I-X_{u}\right)^{-1}$.

Once $\tilde{T}$ is calculated, we calculate $D_{i}+R_{i}$ and $D_{i}-R_{i}$ and that $D_{i}$ and $R_{i}$ are in sequence the row and column summation of $\tilde{T}$ matrix. For accomplishment of the affair, we convert all $D_{i}+R_{i}$ and $D_{i}-R_{i}$ to certain numbers by DEFUZZY method. We will use CFCS (Opricovic \& Tzeng, 2003) for making DEFUZZY in this paper. Furthermore, for CFCS we will have:

If $\tilde{n}_{k}=\left(\lambda_{k}, m_{k}, u_{k}\right) ; k=1,2, \ldots, n$ are triangular Fuzzy numbers and popular $\tilde{n}_{k}^{\text {def }}$ is their certain amount and $L=\min \left(\lambda_{k}\right)$ and $R=\max \left(u_{k}\right) ; k=1,2, \ldots, n$ and $\Delta=R-L$, then: 


$$
\tilde{n}_{k}^{\text {def }}=L+\Delta \times \frac{(m-L)(\Delta+u-m)^{2}(R-\lambda)+(u-L)^{2}(\Delta+m-\lambda)^{2}}{(\Delta+m-\lambda)(\Delta+u-m)^{2}(R-\lambda)+(u-L)(\Delta+u-m)}
$$

Finally, we have two sets of numbers: $\left(D_{i}+R_{i}\right)^{\text {def }}$ which indicate how much macro objectives are important and $\left(D_{i}-R_{i}\right)^{\text {def }}$ which indicate the influencing and impressible items. Generally, if $\left(D_{i}-R_{i}\right)^{\text {def }}$ is negative, opposite objective is in impressible group.

Furthermore, if a diagram is finally drawn, data of $\mathrm{X}$ axis is $\left(D_{i}+R_{i}\right)^{\text {def }}$ and we replace the $\mathrm{Y}$ axis by $\left(D_{i}-R_{i}\right)^{\text {def }}$ numbers obtaining a graph, which can be completed by the information of $\tilde{T}$ matrix (relations among graph elements).

5.9. Determining the strategy nature: In this step, strategies are divided in four aspects of balanced score card by expert opinions and balanced score card specialists.

5.10. Strategy map drawing: Strategy map is provided after determining strategy nature and composition of obtained graphs from previous stages, which could be considered as a foundation for balanced score card implementation.

5.11. Performance indexes: Performance indexes are indicators of short term objectives. Performance indexes should be measurable, quantitative, challengeable, real and compatible with long term and constituent parts of strategies.

\section{Information analysis in Hamshahri newspaper as a media organization}

6.1 Mission and vision appointment: Hamshahri newspaper as a written media organization in Iran with the following mission:

"comprehensive, accurate, fast and high quality presentation of news and information by utilization of the most developed methods and techniques and the most desirable human capitals with the aim of developing addressee's knowledge and awareness in national and international levels across their commitment, participation and explanatory behavior to achieve a more eminent and rich life".

The vision statement of Hamshahri newspaper is also described as follow:

" Hamshahri newspaper as the best written media of the state, and by Islamic-Iranian identification has a credible position among 5 first medias in middle east, and 20 world newspaper, by having a unique position among written medias of country is capable of making required infrastructures for constituent direction of intellectual changes with respect to the society and addressee's requirements and expectations, by utilization of expert, capable and committed human force and permanent competitive advantage among written Medias of country is active, inspirational effective on national, international and domestic changes, having an instructing centre for provision of plots and newspapers required programs, performing application and fundamental researches in media issues, research commercialization and designing efficient and fixed pattern of Medias, having administrative and scientific reference in Media discussions and communicational sciences and pioneer in production and presentation of new ideas in media science by utilization of real, researchbased and dynamic instructional system, trustworthy as an informative and predicate resource by society with reliance on rationality and temperance policy, having most developed technologies and compatible with global standards, having constituent and effective interaction with the domestic and foreign Medias based on balanced and harmony in three needs, profits and stuffs categories, enjoying of most comprehensive centre of Media expert informational Bank (Media science, photo archive,...) in regional and state level, having required qualitative development in all dimensions such as content production, emission and distribution quality in compare to other competitors, enjoying of required 
flexible power in all dimensions across conformity with international, regional and national changes, pioneer in support and attraction of innovators, researchers, and ultramodern of applied and fundamental new research arena in Media and communication zone”.

6.2 Determining strategic implications: with respect to the mission and vision of Hamshahri newspaper, strategic implications are generated as 1. Brand development processes of organizations, 2. Increase in addressee's satisfaction and trust processes of organization and 3. Processes of flexibility power of organization.

6.3 Determination of macro objectives: Macro objectives were identified according to the third table with considering the strategic implications of organization and strategic team.

\section{Table 4}

Macro objectives of Hamshahri newspaper

\begin{tabular}{|c|c|}
\hline Macro objectives & Strategic implication \\
\hline $\begin{array}{l}\text { 01. Creating an appropriate and efficient system for exchange of media content with } \\
\text { other world Media organizations for enrichment of newspaper content and newspaper } \\
\text { brand development } \\
\text { 02. Cost reduction by the aim of reducing dependency on advertisement revenue in } \\
\text { proportion to the total cost. }\end{array}$ & $\begin{array}{l}\text { Brand development processes } \\
\text { of organization }\end{array}$ \\
\hline $\begin{array}{l}\text { 03. Reinforcement of public trust to newspaper in society level under independence } \\
\text { protection against resulting pressures of individuals, groups, social and political } \\
\text { attitudes and tastes and playing ultra aisle role in a space full of political competitions } \\
\text { of Iran present society. }\end{array}$ & $\begin{array}{l}\text { Increase in addressee's } \\
\text { satisfaction and trust processes } \\
\text { of organization }\end{array}$ \\
\hline $\begin{array}{l}\text { 04. Designing, development and application of modern performance evaluation } \\
\text { systems and strategic planning and adoption of efficient methods for promotion and } \\
\text { improvement of productivity in organization } \\
\text { 05. Increasing the service incentive and organizational dependency sensation of } \\
\text { employees by reengineering in promotions, encouragements, evaluation and instruction } \\
\text { system with emphasize on individuals and unit's performance evaluation and also } \\
\text { organizational communication development } \\
\text { 06. Creation and establishment of continual and effective relation among research } \\
\text { activities and newspaper needs in application and guideline levels by the aim of } \\
\text { effective application of research findings in content production processes and } \\
\text { distribution in domestic and foreign markets. }\end{array}$ & $\begin{array}{l}\text { Processes of flexibility power } \\
\text { of organization }\end{array}$ \\
\hline
\end{tabular}

6.4 Internal and external analysis and strategy determination: strategic objectives of Hamshahri newspaper were generated as the second column of the $8^{\text {th }}$ table after performed environmental investigations by expert group by the use of SWOT matrix.

6.5 Allocation of strategies to the macro objective: we will have Table 5 with respect to expert group's opinions and combination of their ideas.

\section{Table 5}

Influencing extent of the strategies on macro objectives with nominal variables

\begin{tabular}{lllllll}
\hline & \multicolumn{2}{l}{ General Objectives } & \multicolumn{3}{c}{} \\
strategic Objectives & $\mathrm{O}_{1}$ & $\mathrm{O}_{2}$ & $\mathrm{O}_{3}$ & $\mathrm{O}_{4}$ & $\mathrm{O}_{5}$ & $\mathrm{O}_{6}$ \\
\hline $\mathrm{S}_{1}$. Content enrichment & $\mathrm{VH}$ & $\mathrm{M}-\mathrm{H}$ & $\mathrm{VL}$ & $\mathrm{VL}$ & $\mathrm{M}$ & $\mathrm{VL}$ \\
$\mathrm{S}_{2}$. Operational eminency in content exchange & $\mathrm{VH}$ & $\mathrm{VL}$ & $\mathrm{VL}$ & $\mathrm{VL}$ & $\mathrm{M}$ & $\mathrm{VL}$ \\
$\vdots$ & $\vdots$ & $\vdots$ & $\vdots$ & $\vdots$ & $\vdots$ & $\vdots$ \\
$\mathrm{S}_{16}$ Increase in customer product portfolio & $\mathrm{L}-\mathrm{M}$ & $\mathrm{L}-\mathrm{M}$ & $\mathrm{L}$ & $\mathrm{VL}$ & $\mathrm{L}$ & $\mathrm{H}$ \\
\hline
\end{tabular}

Strategy designation to macro objectives while changing the above nominal variables to certain data and generation of the range of fourth quarter of each row. 


\section{Table 6}

Influencing extent of the strategies on macro objectives with certain numbers by calculating the fourth quarter

\begin{tabular}{|c|c|c|c|c|c|c|c|}
\hline \multirow[b]{2}{*}{ Strategic Objectives } & \multicolumn{7}{|c|}{ General Objectives } \\
\hline & $\mathrm{O}_{1}$ & $\mathrm{O}_{2}$ & $\mathrm{O}_{3}$ & $\mathrm{O}_{4}$ & $\mathrm{O}_{5}$ & $\mathrm{O}_{6}$ & Fourth quartile \\
\hline $\mathrm{S}_{1}$. Content enrichment & 9 & 6 & 1 & 1 & 5 & 1 & 6.5 \\
\hline $\begin{array}{l}\mathrm{S}_{2} . \text { Operational eminency in content } \\
\text { exchange }\end{array}$ & 9 & 1 & 1 & 1 & 5 & 1 & 6.5 \\
\hline$\vdots$ & $\vdots$ & $\vdots$ & $\vdots$ & $\vdots$ & $\vdots$ & $\vdots$ & $\vdots$ \\
\hline $\mathrm{S}_{16}$. Increase in customer product portfolio & 4 & 4 & 3 & 1 & 3 & 7 & 5 \\
\hline
\end{tabular}

For example, the relation between the first strategy and the third macro objective (by relation intensity of 1 in the $6^{\text {th }}$ table) is not considered, since the acceptable range in this row of the $6^{\text {th }}$ table is between 6.5 and 9 .

Designation is performed for relation between the first strategy and the first macro objective with relation intensity of 9 . Effective significant relations in designation with $\left(^{*}\right)$ signal are determined in the $7^{\text {th }}$ table.

\section{Table 7}

Significant relations for designation of strategies to macro objectives

\begin{tabular}{|c|c|c|c|c|c|c|}
\hline & \multicolumn{6}{|c|}{ General Objectives } \\
\hline Strategic Objectives & $\mathrm{O}_{1}$ & $\mathrm{O}_{2}$ & $\mathrm{O}_{3}$ & $\mathrm{O}_{4}$ & $\mathrm{O}_{5}$ & $\mathrm{O}_{6}$ \\
\hline S1. Content enrichment & $\sqrt{ }$ & & & & & \\
\hline S2. Operational eminency in content exchange & $\sqrt{ }$ & & & & & \\
\hline $\begin{array}{l}\text { S3. Effective relations with other media organizations of } \\
\text { the world }\end{array}$ & $\sqrt{ }$ & & & & & $\sqrt{ }$ \\
\hline $\begin{array}{l}\text { S4. Development of knowledge management and IT } \\
\text { applications in the organization }\end{array}$ & $\sqrt{ }$ & & & & & \\
\hline S5. Brand development & $\sqrt{ }$ & & & & & \\
\hline Addressee trust and satisfaction & $\sqrt{ }$ & $\sqrt{ }$ & & & $\sqrt{ }$ & \\
\hline $\begin{array}{l}\text { S7. creating power in key competency(employee } \\
\text { commitment and independency) and distribution of adequacy } \\
\text { culture, courtliness }\end{array}$ & & $\sqrt{ }$ & & & & \\
\hline $\begin{array}{l}\text { S8. reducing organizational dependency from Tehran } \\
\text { municipality and other economic and political groups }\end{array}$ & & $\sqrt{ }$ & & & & \\
\hline $\begin{array}{l}\text { S9. Developing the evaluation skills and strategic } \\
\text { planning of employee }\end{array}$ & & & $\sqrt{ }$ & & & \\
\hline $\begin{array}{l}\text { S10. redesigning the operations, efficiencies and flexibility } \\
\text { of the organization }\end{array}$ & & & $\sqrt{ }$ & & & \\
\hline $\begin{array}{l}\text { S11. productivity improvement(cost reduction, service } \\
\text { quality) }\end{array}$ & & & $\sqrt{ }$ & & & \\
\hline S12. reinforcement of employee's stimulation needs & & $\sqrt{ }$ & $\sqrt{ }$ & $\sqrt{ }$ & & \\
\hline $\begin{array}{l}\text { S13. development of innovation and creativity culture in } \\
\text { organization }(\mathrm{R} \& \mathrm{D})\end{array}$ & & & & & $\sqrt{ }$ & \\
\hline $\begin{array}{l}\text { S14. attainment of technical knowledge from technical and } \\
\text { scientific societies }\end{array}$ & & & & & $\sqrt{ }$ & \\
\hline S15. maximizing stakeholder value & & & & & & $\sqrt{ }$ \\
\hline S16. increase in customer product portfolio & & & & & & $\sqrt{ }$ \\
\hline
\end{tabular}

6.6 Application of Fuzzy DEMATEL for definition of relationships among the strategies: effective strategies on each of macro objectives are separately investigated with consideration of performed division on the seventh step and are generated as the $8^{\text {th }}$ table for each of communication network 
objectives of the strategy by the use of Fuzzy DEMATEL technique which statement of their calculation is refused.

Table 8

Strategy communication network with segregation of macro objectives

\begin{tabular}{|c|c|c|}
\hline Macro objective & strategies & $\begin{array}{l}\text { Diagraph of the strategy } \\
\text { influence on each other }\end{array}$ \\
\hline $\begin{array}{l}01 . \quad \text { Creating an } \\
\text { appropriate and efficient } \\
\text { system for exchange of } \\
\text { content media with other } \\
\text { media organizations of the } \\
\text { world for... }\end{array}$ & $\begin{array}{l}\text { 1. Content enrichment } \\
\text { 2. Operational eminency in content } \\
\text { exchange } \\
\text { 3. Effective relations with other media } \\
\text { organizations of the world. } \\
\text { 4. Development of knowledge } \\
\text { management and IT applications in the } \\
\text { organization } \\
\text { 5. Brand development } \\
\text { 6. Addressee trust and satisfaction }\end{array}$ & \\
\hline $\begin{array}{l}02 . \quad \text { Cost reduction by } \\
\text { the aim of reducing the } \\
\text { dependency to } \\
\text { advertisement revenue in } \\
\text { proportion to the total cost. }\end{array}$ & $\begin{array}{l}\text { 6. Addressee trust and satisfaction } \\
\text { 7. Creating power in key competency } \\
\text { (employee commitment and } \\
\text { independency) and distribution of } \\
\text { adequacy culture, courtliness } \\
\text { 8. Reducing organizational dependency } \\
\text { from Tehran municipality and other } \\
\text { economic and political groups } \\
\text { 12. Reinforcement of employee's } \\
\text { stimulation needs }\end{array}$ & \\
\hline $\begin{array}{l}03 . \quad \text { Consolidation of } \\
\text { public trust to newspaper in } \\
\text { the society level under } \\
\text { independency protection of } \\
\text { newspapers against } \\
\text { resulting pressures of } \\
\text { individuals, groups, ... }\end{array}$ & $\begin{array}{l}\text { 9. Developing the evaluation skills and } \\
\text { strategic planning of employee. } \\
\text { 10. Redesigning the operations, } \\
\text { efficiencies and flexibility of the } \\
\text { organization. } \\
\text { 11. Productivity improvement(cost } \\
\text { reduction, service quality) } \\
\text { 12. Reinforcement of employee's } \\
\text { stimulation needs }\end{array}$ & \\
\hline $\begin{array}{l}05 . \text { Increase in } \\
\text { organizational service } \\
\text { incentive and dependency } \\
\text { sensation of employees by } \\
\text { reengineering... }\end{array}$ & $\begin{array}{l}\text { 4. Development of knowledge } \\
\text { management and IT applications in the } \\
\text { organization } \\
\text { 13. Development of innovation and } \\
\text { creativity culture in organization(R\&D) } \\
\text { 14. Attainment of technical knowledge } \\
\text { from technical and scientific societies }\end{array}$ & \\
\hline $\begin{array}{l}\text { 06. Creation and } \\
\text { establishment continual } \\
\text { relation among activities ... }\end{array}$ & $\begin{array}{l}\text { 11. Productivity improvement(cost } \\
\text { reduction, service quality) } \\
\text { 15. Maximizing stakeholder value } \\
\text { 16. Increase in customer product } \\
\text { portfolio }\end{array}$ & 1 \\
\hline
\end{tabular}


6.7 Determination of the strategy nature: as discussed before, the strategies are categorized in four balanced score card aspects by balanced score card specialists and expert's opinions in Hamshahri newspaper in this step and are generated in Table 9.

Table 9

Determination of the strategy nature with respect to four balanced score card aspects Symmetrical

\begin{tabular}{|c|c|}
\hline Macro objectives & Balanced score card aspects \\
\hline Content enrichment & Society and public Opinion \\
\hline Operational eminency in content exchange & Internal processes \\
\hline $\begin{array}{l}\text { Development of knowledge management and IT applications } \\
\text { in organization }\end{array}$ & Employees and growth \\
\hline Brand development & Society and public Opinion \\
\hline Addressee trust and satisfaction & Society and public Opinion \\
\hline Increase in organizational flexibility power & Internal processes \\
\hline And ... & And ... \\
\hline
\end{tabular}

6.8 drawing the strategy map: Hamshahri newspaper strategies are categorized in four balance score card according to the balanced score card specialists and expert's opinions and finally is paid to drawing the strategy map in the $8^{\text {th }}$ table with incorporating the diagraph of the strategy influence and its result will be Table10.

\section{Table10: Hamshahri newspaper strategy map}

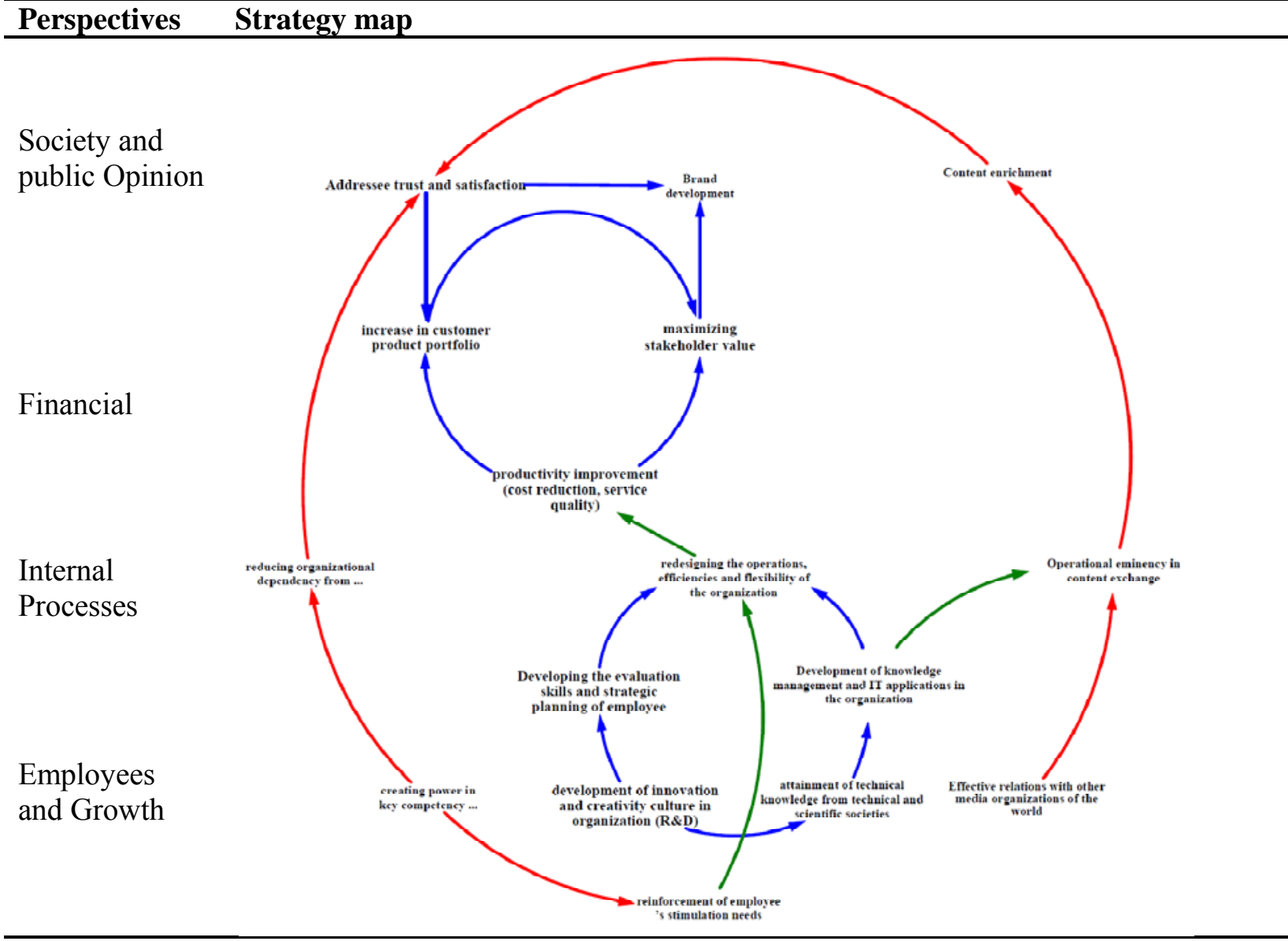

Performance indexes: Finally, the most important indexes of Hamshahri newspaper are identified in the $11^{\text {th }}$ table with respect to Hamshahri newspaper strategies by the use of expert groups. 
Table 11

Performance indexes

\begin{tabular}{|c|c|}
\hline Macro objective & Performance indexes \\
\hline $\begin{array}{l}\text { Content } \\
\text { enrichment }\end{array}$ & $\begin{array}{l}\text { a) The value amount of newspaper } \\
\text { b) Objectivity and equality of published information and news } \\
\text { c) Comprehensiveness of published information and news } \\
\text { d) Reality of published information and news }\end{array}$ \\
\hline $\begin{array}{l}\text { Addressee's trust } \\
\text { and satisfaction }\end{array}$ & $\begin{array}{l}\text { a) The amount of received complaint of customers and addressees } \\
\text { b) The amount of addressee's trust and satisfaction according to voting }\end{array}$ \\
\hline $\begin{array}{l}\text { Operational } \\
\text { competitiveness in } \\
\text { content exchange }\end{array}$ & $\begin{array}{l}\text { a) Diversity of news and image resource in local, national and international } \\
\text { level, from informing and informational and news network in the organization } \\
\text { b) The attractiveness amount of the newspaper form } \\
\text { c) The amount of accuracy and authenticity of the newspaper } \\
\text { d) The rate amount in presenting the day news and information in newspaper }\end{array}$ \\
\hline $\begin{array}{l}\text { Effective relations } \\
\text { with other media } \\
\text { organizations of } \\
\text { the world }\end{array}$ & $\begin{array}{l}\text { a) The number of collaboration contracts and agreements with other media } \\
\text { organization of the world } \\
\text { b) Membrane number in occupational committees in relation to medias and } \\
\text { journalists } \\
\text { c) The amount of exchanged information( input in proportion to output) }\end{array}$ \\
\hline $\begin{array}{l}\text { Development of } \\
\text { knowledge } \\
\text { management and } \\
\text { IT application in } \\
\text { the organization }\end{array}$ & $\begin{array}{l}\text { a) The rate of information exchange in domestic communicational networks } \\
\text { b) The rate of information exchange in foreign communicational networks } \\
\text { c) The portal quality of product supply } \\
\text { d) The quality of collecting, regulating, processing and publication technologies } \\
\text { of news and information } \\
\text { e) Ability of content maintenance } \\
\text { f) The number of instructed personnel about knowledge management in } \\
\text { proportion to the total personnel } \\
\text { g) The percentage of defined instruction hours during attendance in this respect } \\
\text { in proportion to the total instruction hours during attendance }\end{array}$ \\
\hline Brand development & $\begin{array}{l}\text { a) Hamshahri newspaper rank in newspaper ranking of the world } \\
\text { b) Hamshahri newspaper rank in media newspaper ranking of the world } \\
\text { c) Trade name rank of Hamshahri newspaper among other domestic brands } \\
\text { d) Trade name rank of Hamshahri newspaper among other foreign brands }\end{array}$ \\
\hline $\begin{array}{l}\text { Producing power } \\
\text { in key } \\
\text { competencies }\end{array}$ & $\begin{array}{l}\text { a) The attraction number of journalists and writing members based on } \\
\text { professional and competency measures in proportion to the total attracted } \\
\text { individuals } \\
\text { b) The volume of biased news resulting from political and economic } \\
\text { dependencies in the organization }\end{array}$ \\
\hline $\begin{array}{l}\text { Reducing } \\
\text { organizational } \\
\text { dependency of } \\
\text { Tehran and other's } \\
\text { municipality }\end{array}$ & $\begin{array}{l}\text { a) The volume of biased information and news in proving or rejecting the } \\
\text { political flows and economic organizations } \\
\text { b) The amount of accountability and coordination to the city association as the } \\
\text { representative observational institution of people in the organization } \\
\text { c) The dependency extent of Tehran municipality budget in expenditure } \\
\text { providing(in proportion to the total expenditures of the organization) }\end{array}$ \\
\hline
\end{tabular}




\section{Table11}

Performance indexes

\begin{tabular}{ll}
\hline Macro objective & Performance indexes \\
\hline & a) The number of domestic festivals of better works which are held by the \\
organization & b) The number of new ideas presented to suggestion system by personnel \\
c) The percentage of applied new ideas rather than total presented ideas to suggestion & system \\
Development of & d) The percentage of instructional hours meanwhile defined services about innovation \\
innovation and & and creativity in proportion to the total instructional hours. \\
creativity culture in & \\
the organization & e) The percentage of related awards, appointments and promotions in related to the \\
(R\&D) & presented innovations and creativities in proportion to total awards, appointments and \\
promotions in the organization \\
f) The number of new presented plans to operational units by research and instruction \\
center.
\end{tabular}

a) The number of related specialist- scientific congress with journalism and related literatures which are held by organization.

Attainment of $\quad$ b) The number of specialist-scientific festivals and exhibitions related to journalism technical knowledge from technical and scientific societies and related literatures which are held by organization

c) The number of survey- scientific or field-scientific related to journalism and related literatures which are published by the organization

d) The extent of support and profiting from college researches in press activities

e) Profiting from new technologies and equipments in production processes

\section{Increase in customers purchase portfolio}

Reinforcement of employee's incentive needs
a) Revenue ratio to the total costs of the organizations
b) Revenue ratio to the total revenues of the organizations
c) The number of newspaper title
a) The extent of defined job enrichment and satisfying for the organizational personnel
b) The amount of appreciation from personnel for doing their responsibilities
c) Personnel's job improvement opportunities in different task level
d) Personnel's learning and growth opportunities during attendance
e) The amount of personnel's reliance on others for performing their duties
f) The amount of honorable conditions of defined tasks in the organization 


\section{Findings}

Media organizations in the information age are required to have new managerial attitudes and instruments, which incorporate the traditional evaluation methods with new ones. One of the most applied methods is introduced balanced score card which is capable of investigating organizations by segregation of several aspects in achievement of their objectives. Although, researchers paid to the strategy provision and generation of macro objectives after analyzing environmental conditions of a media organization and finally with drawing the strategy map and performance index generation by the use of DEMATEL technique prepared the implementation of a strong system such as balanced score card. The results of this research in a media organization such as Hamshahri newspaper indicated that decision technique such as DEMATEL can be applied by a structured and systematic methodology in designing the strategy map and performance indexes, since this issue was supported in strategy based organizations.

Finally, it is suggested that researchers should enjoy of other nonlinear network solving methods for drawing the strategy map and compare the results by the applied methods such as fuzzy DEMATEL technique.

\section{Acknowledgment}

We are extremely thankful of Hamshahri newspaper personnel and managers as the most titled newspaper in Iran who extremely contributed to this work.

\section{References}

Achterbergh, R., \& Beeres, D. V. (2003). Does the balanced scorecard support organizational viability?, Kybernetes, 32(9/10), 1387-1404.

Akkermans, H., \& Von Oorschot, K. (2000). Developing a balanced scorecard with system dynamics, Journal of the Operational Research Society. 56(8), 931-941.

Alderman, J. D. (1994). Leading the public: The media's focus on crime shaped sentiment. The Public Perspective, 5, 26-27.

Bell, A. (1991). The Language of the News Media. Oxford, England: Blackwell.

Biancamaria, S., Durand, M., Andreadis, K. M., Bates, P. D., Boone, A., Mognard, N. M., Rodriguez, E., Alsdorf, D. E., Lettenmaier, D. P., \& Clark, E. A. (2011). Assimilation of virtual wide swath altimetry to improve Arctic river modeling. Remote Sensing of Environment, 115(2), 373-381.

Chen, Y. J. (2011). Structured methodology for supplier selection and evaluation in a supply chain, Information Sciences, 181(9), 1651-1670.

Cohen, B. C. (1963). The Press and Foreign Policy. Princeton: Princeton University Press.

David, R. F. (1997). Strategic Management. $6^{\text {th }}$ ed., Prentice Hall International, Inc.

Dreier, P. (2005). How the media compound urban problems. Journal of Urban Affairs, 27(2), 193201.

Drucker, P.F. (1974). Management: Tasks, responsibilities, Practices. Harper Business.

Druckman, J.N. (2005). Media matter: How newspaper and television news cover, campaigns and influence voters. Political Communication, 22, 463-481.

Gabus, A., \& Fontela, E. (1973). Perceptions of the world problematique: communication procedure, communicating with those bearing collective responsibility (DEMATEL Report 1), Battelle Geneva Research Centre, Geneva, Switzerland.

Gao, C. Y., \& Peng, D. H. (2011). Consolidating SWOT analysis with non homogeneous uncertain preference information. Knowledge-Based Systems, 24(6), 796-808.

Gerstl, P. C. (2002). Media (Mis) Representations of Education in the 2000 Presidential Election. Educational Policy, 16(1), 37-55. 
Gilens, M. (1999). Why Americans Hate Welfare: Race, Media and the Politics of Antipoverty Policy. Chicago: University of Chicago Press.

Gilliam, F. D., Iyengar, S., Simon, A., \& Wright, O. (1996). Crime in Black and White: The violent, scary world of local news. Harvard International Journal of press/politics, 3(6), 2-23.

Gordon, A. S. (2004). The representation of planning strategies. Artificial Intelligence, 153(1/2), 287 305.

Grosseck, G., \& Holotescu, C. (2011). Teacher education in 140 characters-micro blogging implications for continuous education, training, learning and personal development. ProcediaSocial and Behavioral Sciences, 11, 160-164.

Hall, A. C., Schumann, Guy J. P., Bamber, J. L., \& Bates, P. D. (2010). Tracking water level changes of the Amazon Basin with space-borne remote sensing and integration with large scale hydrodynamic modelling: A review. Physics and Chemistry of the Earth, Parts $A / B / C, 36(7 / 8)$, 223-231.

Hassanzadeh, A. S., Razmi, J., \& Zhang, G. (2011). Supplier selection and order allocation based on fuzzy SWOT analysis and fuzzy linear programming. Expert Systems with Applications, 38(1), 334-342.

Hauttekeete, L., Evens, T., De Moor, K., Schuurman, D., Mannens, E., \& Van de Walle, R. (2011). Archives in motion: Concrete steps towards the digital disclosure of audiovisual content. Journal of Cultural Heritage, 12 (4), 459-465.

Herrera, F., Viedma, E. V., \& Martinez, L. (2000), A fusion approach for managing multi granularity linguistic term sets in decision making. Fuzzy Sets and Systems, 114, 43-58.

Hunger, J. D., \& Wheelen, T. L. (2000). Strategic Management. Premtice Hall.

Isgören, N.C., \& Ayla, C. (2009). Evaluation on textile-apparel education by SWOT analysis Procedia. Social and Behavioral Sciences, 1(1), 1307-1312.

Iyengar, S., \& Kinder, D. (1987). News that Matters. Chicago, University 0f Chicago Press.

Jamieson, K. H. (2003). The press effect: Politicians, journalists, and the stories that shape the political world. New York: Oxford University Press.

Kaplan, P. S., \& Norton, D. P. (2000). The strategy-focused organization: How balanced scorecard companies thrive in the new business environment, Boston. MA: Harvard Business School Press.

Kaplan, R. S., \& Norton, D. P. (2001). The Strategy-Focused Organization: How Balanced Scorecard Companies Thrive in the New Business Environment. Boston. MA: Harvard Business School Press.

Kaplan, R. S., \& Norton, D. P. (2004). Strategy Maps: Converting Intangible Assets into Tangible Outcomes. Harvard Business School Press.

Koch, J. W. (1994). Group identification in political context. Political Psychology, 15(4), 687-698.

Lee, K.L., \& Lin, S.C. (2008). A fuzzy quantified SWOT procedure for environmental evaluation of an international distribution center. Information Sciences, 178(2), 531-549.

Lee, S., Walsh, P. (2011), SWOT and AHP hybrid model for sport marketing outsourcing using a case of intercollegiate sport. Sport Management Review, 14(4), 361-369.

Li, R. J. (1999). Fuzzy method in group decision making. Computers and Mathematics with Applications, 38(1), 91-101.

Lin, C. J., \& Wu, W.W. (2008). A Causal analytical method for group decision making under Fuzzy environment. Expert Systems with Applications, 34, 205-213.

Linard, K., \& Yoon, J. (2000). The dynamics of organizational performance development of a dynamic balanced scorecard. The First International Conference of System Thinking in Management. 359-364. 
Liu, T. T., McConkey, B. G., Ma, Z. Y., Liu, Z. G., Li, X., \& Cheng, L. L. (2011), Strengths, Weaknessness, Opportunities and Threats Analysis of Bio energy Production on Marginal Land. Energy Procedia, 5, 2378-2386.

Makhijani, N., \& Creelman, J. (2008). How leading organizations successfully implement corporate strategy with the balanced scorecard. The OTI Thought Leadership Series, 1, 1-16.

Manteghi, N., \& Zohrabi, A. (2011). A proposed comprehensive framework for formulating strategy: a Hybrid of balanced scorecard, SWOT analysis, porter's generic strategies and Fuzzy quality function deployment. Procedia-Social and Behavioral Sciences, 15, 2068-2073.

Markovska, N., Taseska, V., \& Jordanov, J. P. (2009). SWOT analyses of the national energy sector for sustainable energy development, Energy. 34(6), 752-756.

Mihaela, S., Moraru, A., Adriana-Elena, T., \& Monica, F. (2011). An organizational development program in the preschool educational institution. Procedia-Social and Behavioral Sciences, 15, 9981002 .

Misra, R. D., \& Murthy, M. S. (2011). Jatropa-The future fuel of India. Renewable and Sustainable Energy Reviews, 15(2), 1350-1359.

Nikolaou, I. E., \& Evangelinos, K. I. (2010). A SWOT analysis of environmental management practices in Greek Mining and Mineral Industry. Resources Policy, 35(3), 226-234.

Okumus, F. (2002). Can hospitality researchers contribute to the strategic management literature?, International Hospitality Management, 21(2), 105-110.

Olve, N. G., \& Sjöstrand, A. (2002). The Balanced Scorecard. John Wiley \& Sons.

Opricovic, S., \& Tzeng, G. H. (2003). Defuzzification Within a multi criteria decision model, Journal of Uncertainty. Fuzziness and Know ledge based Systems, 11(5), 635-652.

Page, B., Shapiro, R., \& Dempsey, G. (1987). What moves public opinion? American Political Science Review, 81, 23-43.

Parenti, M. (1993). Inventing Reality: The Political of News Media Reality. (2 ${ }^{\text {nd }}$ ed.), New York: St. Martin's Press.

Pearce, J. A., \& David, F. R. (1987). Corporate Mission Statements: The Bottom Line, Academy of Management Executive, 1(2), 109-115.

Ralph, F. S. (2007). Business Process Management and the Balanced Scorecard: Using Processes as Strategic Drivers. John Wiley \& Sons, Inc.

Raval, V., \& Fichadia, A. (2007). Risks, Controls, and Security: Concepts and Applications. John Wiley \& Sons.

Rizzi, F., Frey, M., \& Iraldo, F. (2011), Towards an integrated design of voluntary approaches and standardization processes: An analysis of Issues and trends in the Italian regulation on ground coupled heat pumps. Energy Conversion and Management, 52(10), 3120-3131.

Roed-Larsen, S., \& Stoop, J. (2011). Modern accident investigation-Four major challenges. Safety Science, doi:10.1016/j.ssci.2011.03.005.

Sanagustin Fons, M. V., Mosene Fierro, J. A., \& Patino, M. G. (2011). Rural tourism: A sustainable alternative. Applied Energy, 88(2), 551-557.

Siddique-E-Akbor, A. H. M., Hossain, F., Lee, H., \& Shum, C. K. (2011). Inter-comparison study of water level estimates derived from hydrodynamic-hydrologic model and satellite altimetry for a complex deltaic environment. Remote Sensing of Environment, 115(6), 1522-1531.

Soley, L. (1992). The news shapers: The sources who explain the news. New York: Praeger.

Tohidi, H., Jafari, A., \& Azimi Afshar, A. (2010). Strategic planning in Iranian educational organizations. Procedia Social and Behavioral Sciences, 2, 3904-3908.

Valentino, N. A. (1999). Crime news and the priming of racial attitudes during evaluations of the president. Public Opinions Quarterly, 63, 293-320. 
Van Dijk, T. (1998). Opinions and ideologies in the press, In A. Bell \& p. Garrett (Eds.), Approaches to media discourse. 21-63, Oxford, England: Blackwell.

Wang, K. J., \& Hong, W. C. (2011). Competitive advantage analysis and strategy formulation of airport city development-The case of Taiwan. Transport Policy, 18(1), 276-288.

Wang, R. C., \& Chuu, S. J. (2004). Group decision making using a fuzzy linguistic approach for evaluating the flexibility in a manufacturing system. European Journal of Operational Research, 154, 363-572.

Wu, W. W., \& Lee, Y. T. (2007). Developing global managers competencies using the fuzzy DEMATEL method. Expert Systems with Applications, 32, 499-507. 